\title{
Capturing, Classification and Concept Generation for Automated Maintenance Tasks
}

\author{
${ }^{1}$ M. Farnsworth ${ }^{*}$ and ${ }^{2} \mathrm{~T}$. Tomiyama (1) \\ ${ }^{1}$ EPSRC Through Life Engineering Services Centre, Cranfield University, College Road, Bedfordshire, MK43 OAL, UK \\ ${ }^{2}$ Manufacturing and Materials Department, Cranfield University, College Road, Bedfordshire, MK43 OAL, UK
}

Maintenance is an efficient and cost effective way to keep the function of the product available during the product lifecycle. Automating maintenance may drive down costs and improve performance time; however capturing the necessary information required to perform certain maintenance tasks and later building automated platforms to undertake them is very difficult. This paper looks at the creation of a novel methodology tasked with firstly the capture and classification of maintenance tasks and finally conceptual design of platforms for automating maintenance.

\section{Background}

There has been a recent shift to service-based models which now sees the asset being leased to the end user with a maintenance provider contracted to ensure availability of the asset [1-2]. An example of this is Bombardier Transportation providing the maintenance to East Midlands trains for the class 222 train sets. Such a business model provides motivation for improving the maintenance function in order to reduce throughlife costs and maximize profits on those contracts.

Many strategies exist in trying to reduce through-life costs, such as the integration of robustness and self-healing into product designs [3]. Recent decades have seen an increasing use of robots within manufacturing processes. The speed, power, availability, productivity, and improved accuracy of robots have had significant impact in reducing manufacturing costs while improving production quality.

It therefore seems logical to explore the possibilities of robots being used within the maintenance function to provide the same benefits as are found by their use in the manufacturing process. However, so far applications of robots to maintenance have been limited to mostly monitoring and inspection tasks [4]. Most of them are non-autonomous robots (e.g., remote-controlled) equipped with cameras, sensors, and master-slave controlled manipulators. Exceptionally, a few robots are capable of performing their inspection tasks autonomously [5].

Maintenance is the process of keeping something in good order. The eventual aim of this research is to investigate the feasibility of introducing robots to maintenance beyond simple monitoring and inspection tasks. However, maintenance is known to have a number of characteristics that are not found in the process of manufacturing of new products. Among others, maintenance is often irregular, nonuniform, non-deterministic and non-standardised.

As its first step, this paper looks to develop a novel methodology towards the capture, classification and concept generation of maintenance tasks. This begins with a brief overview of the task classification methodology and the industrial engineering techniques used in section 2. This is followed with an outline of the concept generation methodology that looks to link the captured information from the task classification with concept designs that can perform such tasks in an automated way. Finally conclusions are drawn and future work outlined.

\section{Maintenance task classification}

Industrial Engineering (IE) techniques fall into two basic categories; they are either used for analysis of existing processes or improvement of those processes. Reported uses of IE within maintenance activities tend to describe how techniques are used for the latter, either by increasing their efficiency or improving their planning. So the Single Minute Exchange of Dies (SMED) techniques are used to reduce setup times [6] and scheduling rules have been used to improve repair system performance within the system's existing constraints (e.g. labour hours, repair facility availability) [7].

As the focus of this methodology is the analysis of movement, IE techniques that are designed for use in describing motion would appear most relevant. On a higher level, maintenance tasks can also be recorded and defined using simple process flow charts to capture the main tasks and decisions within it.

In order to evaluate the proposed task classification methodology a number of maintenance case studies need to be performed [8]. Below is an example of maintenance in the field on a class 222 diesel engine train undercarriage. The class 222 is a diesel-electric multiple unit high speed train. Underneath each carriage on the train is a diesel engine that drives an electrical generator, which then drives electric traction motors. The entire undercarriage units are shielded by a series of side skirts. The electric traction motor drives a pair of bogey wheels through a final drive gearbox. One of the regular maintenance tasks on the gearbox involves checking and analysing of the gearbox oil. A breakdown of the generic steps required to perform this 
maintenance is shown in table 1 , and the gearbox is shown in figure 2 .

The task classification methodology leads to the creation of a number of industrial engineering process and motion information of the maintenance task involved. For the case study maintenance example this includes video information, process flow charts, Therbligs and SIMO chart motion information.

The aluminium oil filler cap incorporates a magnetised steel rod with knurled markings that denote the maximum and minimum oil levels. It is retained in the cast iron gearbox casing by a bayonet fitting. The cap is removed and inspection of the steel rod is undertaken and followed with removal of an oil sample for analysis. A process flow chart for this maintenance is shown in figure 3 .

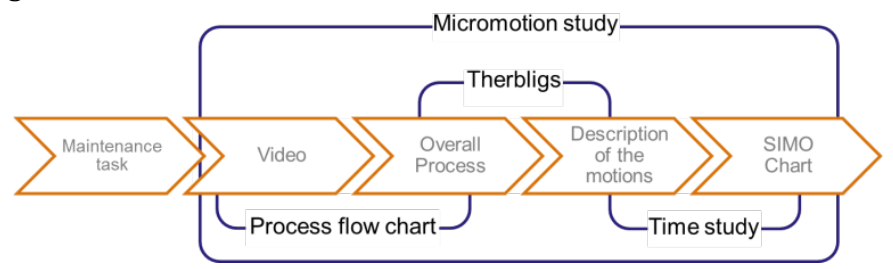

Figure 1. Task classification methodology

Table 1. Checking Oil Level Breakdown

\begin{tabular}{ll}
\hline Step & Description \\
\hline 1 & Assemble sampling device \\
2 & Remove filler cap \\
3 & Visually inspect oil on spigot for contamination \\
4 & Wipe spigot \\
5 & Replace filler cap \\
6 & Remove filler cap and check oil level point on spigot \\
7 & Take oil sample \\
8 & Replace filler cap \\
\hline
\end{tabular}

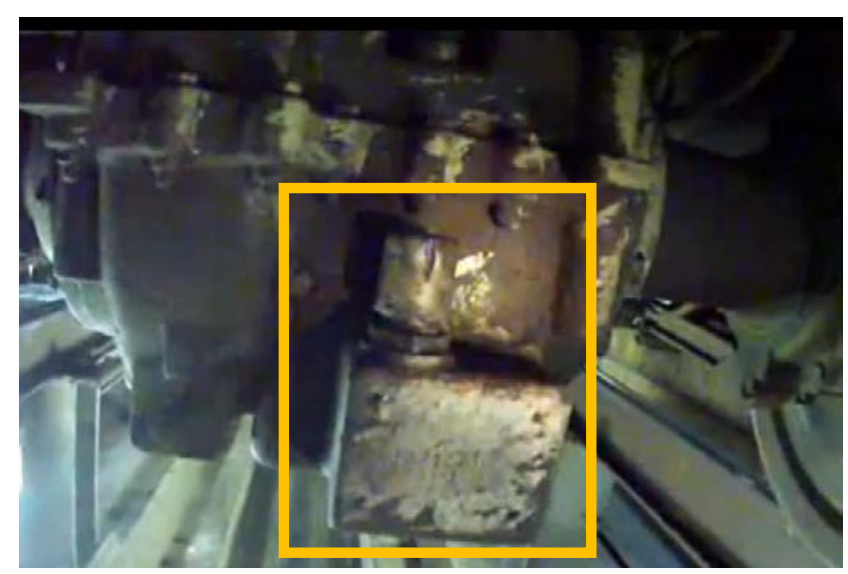

Figure 2. Gearbox oil filler

A number of issues were identified during the process of oil filler maintenance. An oil-tight seal is produced because the elongated inside of the aluminium cap has a close fit to the accurately-bored hole in the casing. Consequently the cap can be quite challenging to remove - usually requiring the shaft of a long screwdriver to lever it out. Bronze particles produced by wear of the brushes in the gearbox will not be attracted to the magnetised steel rod; however they will cause the oil to have an orange tint which can be identified by an experienced maintenance fitter. Similarly water contamination can be identified by sight without having to wait for the results of the laboratory analysis of the oil sample.

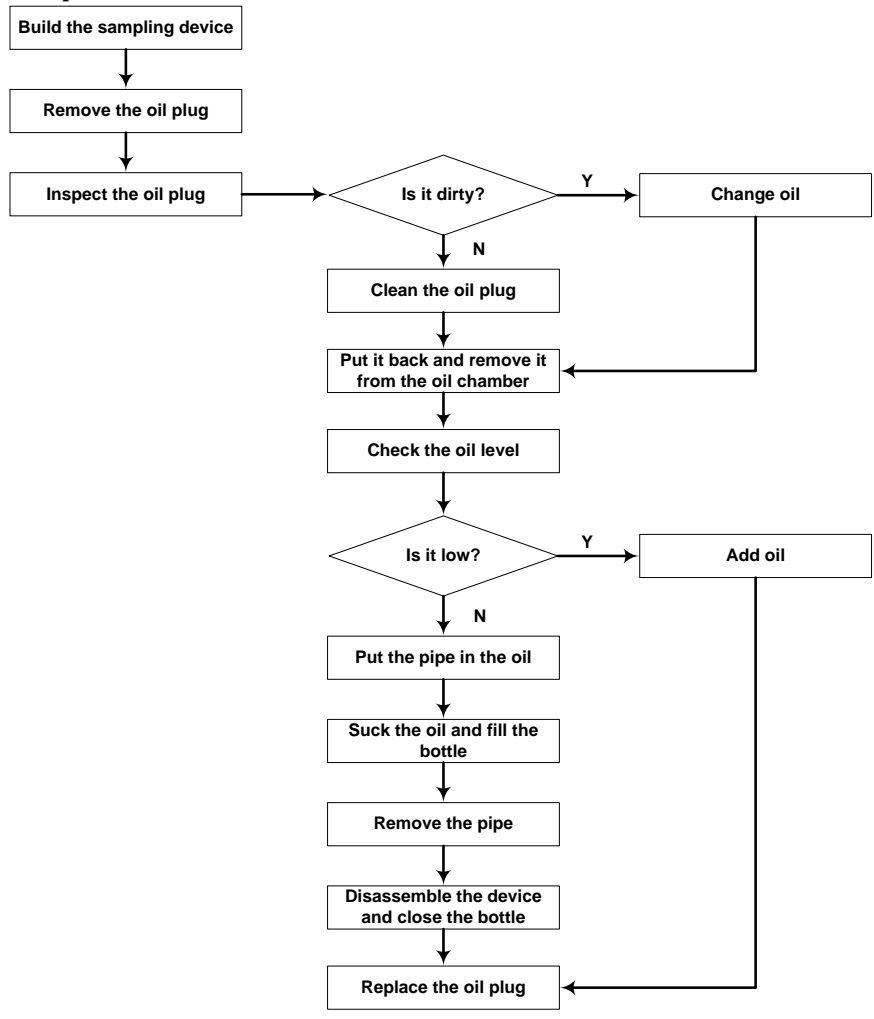

Figure 3. Process flow chart for sampling oil filler

Table 2. Therbligs step seven - put the pipe in the oil

\begin{tabular}{lll}
\hline $\begin{array}{l}\mathrm{N}^{\circ} \text { of } \\
\text { motion }\end{array}$ & Description & Therbligs \\
\hline 1 & Search for the sampling device & Search \\
2 & Find the sampling device & Find \\
3 & Grasp the sampling device & Grasp \\
4 & Search for the pipe of the sampling device & Search \\
5 & Find the pipe of the sampling device & Find \\
6 & Grasp the pipe of the sampling device & Grasp \\
7 & $\begin{array}{l}\text { Move the sampling device to the oil } \\
\text { chamber }\end{array}$ & Transport loaded \\
8 & Move the pipe to the oil chambers hole & Transport loaded \\
9 & $\begin{array}{l}\text { Position the bottom of the pipe in front of } \\
\text { the oil chambers hole }\end{array}$ & Position \\
10 & Put the bottom of the pipe in the hole & Transport loaded \\
11 & Release the pipe & Release \\
\hline
\end{tabular}

A detailed breakdown of the motions required to perform a specific step of the oil filler maintenance task is shown in table 2. Here the methodology captures ten motions for the task 'Put the Pipe in the Oil', highlighting the often large number of motions required to perform what would seem to be a simple task. Finally it is also possible to gather information on the time taken and importantly the left or right hand motions required for each step of the maintenance task as seen in figure 4. This is important as future automated solutions may include multiple robotic arms or find the task decomposed into a number of automated or robotic solutions, each one equipped to perform one motion or step of the maintenance task in a collaborative way. 

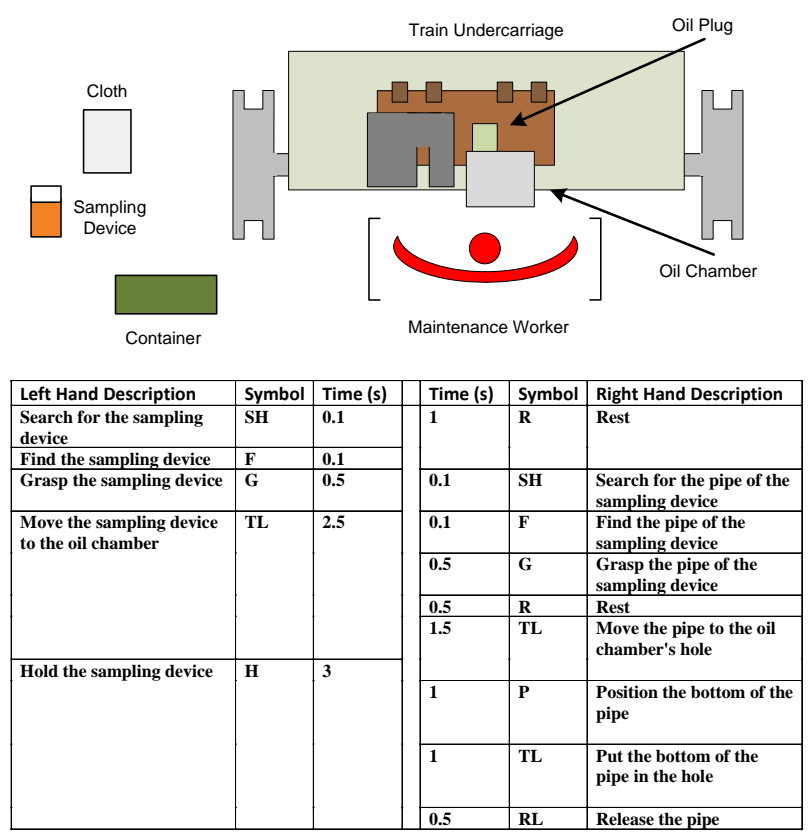

Figure 4. SIMO chart step seven - put the pipe in the oil

\section{Conceptual design for automated maintenance}

The next stage towards automating the maintenance process is to conceive of and build platforms or systems that are able to carry out or aid the maintenance task. Engineering design research has resulted in the formulation of a number of systematic methodologies over the past few decades [9][10].

In order to undertake conceptual design, a list of requirements is abstracted to identify the essential problems of the system [9]. In this instance each of the decomposed 'unit tasks' created in the maintenance task classification step essentially fulfil the overall functionality of that required system.

One method able to exploit such a construction is the morphological table. A powerful combinatorial tool, it utilizes the principles of morphological thinking to guide the creation of conceptual designs through a systematic combination of all possible combinations of fragments that together can constitute a system [10]. Here a visual exploration of the design space is undertaken with the functions represented as our maintenance 'unit tasks' are listed against the means to achieve each of those functions in a two dimensional matrix [10].

\subsection{Physical, cognitive and information phenomena}

In order to aid the process of conceptual design for automated maintenance the standard morphological table has been adapted. As discussed previously the task classification process creates a series of individual 'unit tasks' that capture the main processes of the maintenance task undertaken.
In order to build a system that can perform the entire maintenance task in an automated fashion it is important to go beyond simple hardware and look into more detail the motions and information required to complete a particular 'unit task'. Here we adapt the functions of the morphological table to include information necessary for automation, for example how much force or torque is required to unscrew a bolt, or Cartesian coordinates when looking to transport an object or tool. Also we use knowledge at the granularity of physical phenomena associated with a particular function as shown in table 3 .

Successfully completing the maintenance task outlined previously requires the ability to undertake certain cognitive functions [11]. In the case of the oil filler example, the ability to search for and find the sampling device, a task which requires suitable object recognition algorithms along with the means to gather the necessary information to act upon. Finally the decomposition of the maintenance task allows for the possibility of multiple systems accomplishing specific tasks, in particular for example the application of collaborative or swarm robotics. This it brings with it a whole new challenge as communication and coordination is needed between these individual systems if they are to achieve each maintenance step successfully.

Table 3. Physical, cognitive and information phenomena

\begin{tabular}{|c|c|c|c|c|}
\hline & Means & & & \\
\hline $\begin{array}{l}\text { Function } 1 \\
\text { 'Grasp' }\end{array}$ & $\begin{array}{l}\text { Force + } \\
\text { Friction }\end{array}$ & Suction & $\begin{array}{l}\text { Magnetic } \\
\text { Attraction }\end{array}$ & $\begin{array}{l}\text { Electrostatic } \\
\text { Force }\end{array}$ \\
\hline $\begin{array}{l}\text { Function } 2 \\
\text { 'Find' }\end{array}$ & $\begin{array}{l}\text { Object } \\
\text { Recognition }\end{array}$ & $\begin{array}{l}\text { Classifier } \\
\text { Based }\end{array}$ & $\begin{array}{l}\text { Case Based } \\
\text { Lookup Table }\end{array}$ & $\begin{array}{l}\text { Pattern } \\
\text { Recognition }\end{array}$ \\
\hline $\begin{array}{l}\text { Function } 3 \\
\text { 'Signal' }\end{array}$ & Infra Red & Sound & Ultrasonic & Laser \\
\hline
\end{tabular}

The adaptation of the proposed morphological table is designed so as to best link up with the previous maintenance task methodology so as to provide a 'joined-up' process for capturing, classification and concept design of automated maintenance solutions. Table 4 highlights this link with the functional decomposition focusing on the individual 'unit tasks' and their related process and motion characteristics, there related types and the level of solution. Here the level (High or Low) relates to whether the solution is at its most base level, for example our physical phenomena or a higher, more complex level built upon other actions. An example is the Therblig motion 'Assemble' which itself can consist of the motions 'Plan', 'Search', 'Find', 'Hold', and 'Position'.

An overview of how the methodology is able to capture and classify maintenance tasks and link these with conceptual design is shown in figure 5. Here a small section of the main processes for the oil filler maintenance example are expanded to show their associated motions and in the case of 'Grasp', the associated solutions to perform this particular motion. Included are also some characteristics required to perform the motion in an automated fashion, with the ideal strength and duration noted.

Table 4. Morphological table for automated maintenance (left) and examples (right)

\begin{tabular}{|c|c|c|c|c|c|c|c|c|c|c|c|c|c|}
\hline \multicolumn{3}{|c|}{ Functional Decomposition } & \multicolumn{2}{|l|}{ Means } & \multirow{2}{*}{$\begin{array}{l}\text { Level } 1 \\
\text { Hold the } \\
\text { screwdriver }\end{array}$} & \multirow{2}{*}{$\begin{array}{l}\text { Level } 2 \\
\text { N/A }\end{array}$} & \multirow{2}{*}{$\begin{array}{l}\text { Level } 3 \\
\text { Operation }\end{array}$} & \multirow{2}{*}{$\frac{\text { Type }}{\text { Action }}$} & \multirow{2}{*}{$\begin{array}{l}\text { Function } \\
\text { Grasp }\end{array}$} & \multicolumn{4}{|l|}{ Solutions } \\
\hline Unit Task & Function & Type & Solution & Solution & & & & & & $\begin{array}{l}\text { Force + } \\
\text { Friction }\end{array}$ & $\begin{array}{l}\text { Geometric } \\
\text { Constraint }\end{array}$ & Suction & $\begin{array}{l}\text { Magnetic } \\
\text { Attraction }\end{array}$ \\
\hline Unit Task 1 & Function 1 & Action & High & Low & Lift off body & N/A & Operation & Cognitive & Time & Mechanical & Digital & Signal & \\
\hline Unit Task 2 & Function 2 & Cognitive & Low & Low & $\begin{array}{l}\text { Assemble } \\
\text { Bottle }\end{array}$ & $\begin{array}{l}\text { Order } \\
\text { pieces }\end{array}$ & Operation & Cognitive & Plan & $\begin{array}{l}\text { Markov } \\
\text { Tree }\end{array}$ & $\begin{array}{l}\text { Case Based } \\
\text { Lookup }\end{array}$ & $\begin{array}{l}\text { Node } \\
\text { Graph }\end{array}$ & \\
\hline Unit Task 3 & Function 3 & $\begin{array}{l}\text { Information } \\
\text { Transfer }\end{array}$ & Low & Low & Is It Clean? & No & $\begin{array}{l}\text { Surface } \\
\text { Treatment }\end{array}$ & Action & Polishing & $\begin{array}{l}\text { Force + } \\
\text { Friction }\end{array}$ & $\begin{array}{l}\text { Transferred } \\
\text { Thermal }\end{array}$ & & \\
\hline
\end{tabular}




\section{Build Device $\rightarrow$ Remove Oil Plug $\rightarrow$ Inspect Oil Plug \\ Search for sampling device \\ Find sampling device \\ Grasp sampling device \\ Force + Friction | Geometric Contraint | Suction | Magnetic Attraction \\ Strength | Duration}

Figure 5. Concept generation breakdown

The aim of this methodology is to provide designers with a knowledge base that can guide them towards the conception of automated or robotic solutions to maintenance tasks. It was asserted in section 1 that key characteristics of maintenance are that it is irregular, non-uniform, non-deterministic and nonstandardised. The gearbox oil filler example highlights some of these irregularities, with the variability in trying to pry open the oil cap often requiring additional tools or increased force to be used as a result of age, dirt and degradation. The standard morphological table is often used to build a specific solution to a particular problem. However in maintenance the problem characteristics can easily shift, which in turn means the solution needs to be able to adapt to these changes. The adapted morphological table allows for designers to identify where variation can occur and how best to deal with it in regards to conceptualising a solution. This could for example lie within cognitive reasoning with an automated solution querying its input information and deciding upon a specific action to take to complete a specific step. For example applying more force then has currently been classified for that motion.

If we look again at our gearbox oil filler maintenance example this requires certain functions such as the ability to perform cleaning, in this instance the oil plug itself. If undertaken by a human this basic task can simply require the use of a cloth, water and some force to clean the asset until it is no longer dirty. It seems rather simple, but relies on human capabilities that are not inherent to robots. Requiring agility and dexterity to use the cloth correctly, and the ability to detect the dirt and decide when the task is complete.

In a standard morphological table this function (clean oil plug) is solved with means such as 'compressed air' or 'cloth'. Here the standard approach falls down. Classifying the function as 'clean oil plug' and other functions at similar levels of granularity often associated with the standard approach does not provide the necessary information required for automation. Unless a highly sophisticated automated or robotic solution is present, interpreting 'clean oil plug' and then performing the necessary actions or motions will prove very difficult. The methodology presented overcomes this by focusing on the complete motions and reasoning required to complete a particular 'unit task'. Therefore designers can look to create solutions which have some level of completeness, be they completely automated, or semiautomated with some tasks passed on to humans in some form of collaboration.

The methodology presented has been developed to aid designers to build solutions to solving more complex tasks, in this case automated maintenance. It can help designers make decisions on what can be automated and what can't be, on whether solutions require highly intelligent robotic solutions, or whether they simply need simpler automated mechanical solutions guided by humans. The methodology decomposes the maintenance task in such a way that it allows designers the choice of whether to build a single solution or if applicable and beneficial, design multiple specific solutions to each step of the maintenance process. This is further aided with a process for outlining how these solutions may have to communicate and cooperate in order to complete a task. The methodology can also help identify when automation is not possible or perhaps not required. This allows designers to rethink designs of the assets undergoing maintenance in order to aid automation, a 'design for maintenance' for example. A future designer looking to build a 'oil filler' maintenance robot would in this example have to incorporate abilities for navigation and sensing to reach the target, some level of manipulation with a gripper tailored to the right shape of the cap and enough force to pry open and retrieve the sample.

\section{Conclusions and future work}

An investigation into the role automation and robotics can play in industrial maintenance was undertaken in this research. This revolved around the development of a novel methodology for the capture, classification and conceptual design of automated platforms for industrial maintenance. An industrial case study based around the maintenance of a class 222 diesel engine train undercarriage was used to validate the proposed methodology. The results point to a successful implementation of the methodology in both the task classification and conceptual design approach outlined in this paper. Future work is needed however to improve the current IE techniques used to provide more detail to aid automation with a look to develop an automated tool for building conceptual design ideas from the task classification information captured during the methodology.

\section{Acknowledgments}

The authors wish to thank H. Akrout, D. Anson, G. Bianchini, A. Neveur, C. Trinel, and Bombardier Transportation UK for their support and valuable assistance during this research. This work was funded by the EPSRC, grant number EP/1033246/1 through the kind support of the EPSRC Centre for Innovative Manufacturing in Through-life Engineering Services.

\section{References}

[1] Takata, S., Kimura, F., van Houten, FJAM., Westkamper, E., Shpitalni, M., Ceglarek, D., and Lee, J., (2004) Maintenance: changing role in life cycle management. Annals of CIRP, 53:643-655.

[2] Zhang, Z., and Chu, X., (2010) A new approach for conceptual design of product and maintenance, International Journal of Computer Integrated Manufacturing, 23:603-618.

[3] Bell, C., McWilliam, R., Purvis, R., and Tiwari, A., (2013) On concepts of selfrepairing systems. Measurement and Control. 46:176-179

[4] Tur, J., Garthwaite, W., (2013) Robotic devices for water main in-pipe inspection: A survey. Journal of Field Robotics. 47:491-508

[5] Dobie, G., Summan, R., Pierce, S. G., Galbraith, W., \& Hayward, G. (2011). A Noncontact Ultrasonic Platform for Structural Inspection. IEEE Sensors Journal, 11(10), 2458-2468. doi:10.1109/JSEN.2011.2138131

[6] Cakmakci, M., (1995) Process improvement: Performance analysis of the setup time reduction-SMED in the automobile industry, International Journal of Advanced Manufacturing Technology 41:168-179.

[7] Dutta, U., and Maze, T.H., (1987) Application of Industrial Engineering Techniques in Transit Maintenance. ITE Journal, 57:45-49.

[8] Akrout, H., Anson, D., Bianchini, G., Neveur, A., Trinel, C., Farnsworth, M., and Tomiyama. T., (2013) Maintenance Task Classification: Towards Automated Robotic Maintenance for Industry. Procedia CIRP. 11:367-372

[9] Pahl, G., Beitz, W., Feldhusen, J., and Grote, K. H., (2007) Engineering Design - A Systematic Approach, London: Springer-Verlag London Limited.

[10] George. D.J., (2012) Concept Generation Using Morphological and Options Matrices. Thesis, Clemson University

[11] Vongbunyong, S., Kara, S., and Pagnucco, M., Application of cognitive robotics in disassembly of products, CIRP Annals - Manufacturing Technology, Volume 62, Issue 1, 2013, Pages 31-34, ISSN 0007-8506, 
2014-04-24

\section{Capturing, classification and concept generation for automated maintenance tasks}

Farnsworth, Michael

Elsevier

M. Farnsworth, T. Tomiyama, Capturing, classification and concept generation for automated maintenance tasks, CIRP Annals - Manufacturing Technology, Volume 63, Issue 1, 2014 , Pages 149-152

http://dx.doi.org/10.1016/j.cirp.2014.03.093

Downloaded from Cranfield Library Services E-Repository 